\title{
Is the clinical manifestation of anaphylaxis in children influenced by the trigger of reaction?
}

\author{
Izabela Tarczoń ${ }^{1}$, Urszula Jedynak-Wąsowicz², Grzegorz Lis², Tomasz Tomasik², Piotr Brzyski³, Ewa Cichocka-Jarosz²
}

1"Przyladek Zdrowia", Krakow, Poland

${ }^{2}$ Department of Paediatrics, Jagiellonian University Medical College, Krakow, Poland

3"Dziupla" Statistical Analysis, Krakow, Poland

Adv Dermatol Allergol 2021; XXXVIII (5): 788-797

DOI: https://doi.org/10.5114/ada.2020.95650

\begin{abstract}
Introduction: The number of anaphylaxis diagnoses in children is rising, being still based on the clinical picture. Aim: To determine whether triggers of anaphylaxis influence its clinical characteristics in children and adolescents. Material and methods: The study group included 114 children (5 months-17 years, mean age: $8.0 \pm 4.8$ years), (66\%: boys) with the episode of anaphylaxis up to 1 year back. Medical data were entered to the NORA Registry by means of a validated structured on-line questionnaire.

Results: Three most frequent triggers of anaphylaxis were: insect venom (47.4\%), food (35.1\%), drugs (5.3\%), with a predominance of food (egg white, cow's milk, nuts and peanuts) in the 0-6 years age group, while insect venom (bee predominance) in the 7-17 years age group $(p=0.016)$. Clinical manifestations differed between food vs. venom allergic reactions and presented as gastro-intestinal (GI) $(61.4 \%)(p=0.004)$, respiratory (RS) $(93.9 \%)$ $(p=0.036)$, and cardiovascular (CVS) $(74.6 \%)(p=0.022)$ symptoms. Among objective symptoms, vomiting was the most common symptom in the $0-2$ years age group $(47.1 \%)(p=0.006)$, while hypotension in those aged $7-12$ years $(40 \%)(p=0.010)$. Severity of symptoms evaluated as Mueller's grade (IV- $74.5 \%)$ and as Ring and Messmer's grade (III-65.8\%), depended on the trigger ( $p=0.028, p=0.029$, respectively). Life-threatening symptoms occurred in 26 children (fall of the blood pressure $-22 \%$, loss of consciousness $-4.4 \%$ ).

Conclusions: The clinical manifestation of anaphylaxis in children is both trigger and age dependent, irrespective of the gender. A typical patient with food anaphylaxis was younger, presenting predominantly Gl symptoms, while a typical patient with venom anaphylaxis was older, with mostly cardiovascular symptoms.
\end{abstract}

Key words: anaphylaxis, children, trigger of anaphylaxis, clinical manifestation.

\section{Introduction}

Anaphylaxis remains an important clinical issue in children.

Anaphylaxis is a clinical diagnosis, and it is based on identification of the characteristic symptoms that develop within minutes to a few hours following exposure to a known or potential trigger [1]. The widely used NAID/ FAAN clinical criteria provide over $95 \%$ certainty in anaphylaxis diagnosis [2].

There are 23 known scales to determine severity of anaphylaxis [3], out of which Mueller's scale is typically used to evaluate anaphylaxis following insect venom [4], Sampson's scale for food-triggered anaphylaxis [5], Ring and Messmer's scale is used to determine severity of anaphylaxis mostly in the German-speaking countries [6], as well as World Allergy Organization (WAO) scale and Brown's scale originated from Australasia becomes more and more common [7]. Severity levels vary when evaluated with different scales, especially in case of anaphylaxis triggered by foods and medications [3]. Therefore, there is an increasing need for a homogenous methodology for diagnosis and classification of anaphylaxis, in particular in case of more severe symptoms [8]. A profile of the clinical symptoms may vary with age. There are only a few studies that evaluate this issue [9-11].

\section{Aim}

The aim of the study was to identify triggers of anaphylaxis and their influence on the clinical symptoms presented by the paediatric and adolescent patients treated

Address for correspondence: Ewa Cichocka-Jarosz MD, PhD, Assoc. Prof., Department of Paediatrics, Jagiellonian University Medical College, 265 Wielicka St, 30-663 Krakow, Poland, phone/fax: +48 1265820 11, e-mail: mijarosz@cyf-kr.edu.pl Received: 4.04.2020, accepted: 27.04.2020. 
in one of the tertiary paediatric centres in Poland, and to compare them to the European Anaphylaxis Registry data collected from the multiple paediatric centres. We are still working on the third report that will summarize diagnostic procedures employed to analyse the presented material.

\section{Material and methods}

Data regarding 126 children in the NORA Registry (Network of Severe Allergic Reactions) were derived from validated structured on-line questionnaires. That included each patient's medical history and clinical evaluation of the symptoms in Ring and Messmer's scale (R\&M) upon admission for diagnostics and/or medical intervention due to an episode of anaphylaxis between September 2015 and March 2019. The Registry's administrators confirmed and positively verified 114 questionnaires (90.5\%). The study group included 114 children aged 5 months to 17 years (mean age: $8.0 \pm 4.8$ years), with a male predominance (76 boys, 66\%) in all age groups: $0-2$ years $(n=17,64.7 \%)$, $3-6$ years $(n=32,75 \%), 7-12$ years $(n=40,62.5 \%)$, $\geq 13$ years $(n=25,64 \%)$.

The parents or caregivers of the patients, and all the children older than 16 years signed voluntary informed consent forms to participate in the questionnaire study. The study was approved by the Ethics Committee of the Jagiellonian University (122.6120.250.2015). The work was supported by Jagiellonian University Medical College work funds (K/ZDS/006266). The presented study was a followup of a single-centre analysis, which was previously created in cooperation with the European Anaphylaxis Registry [12].

\section{Statistical analysis}

Qualitative data were presented as counts and percentages whereas quantitative data were given as means and standard deviations (SD). Between-group comparisons of qualitative variables were analysed by $\chi^{2}$ test; when expected frequencies in at least $20 \%$ of cells were lower than 5, the exact Fisher test was used for $2 \times 2$ tables and Fisher-Freeman-Halton $\chi^{2}$ test in the other cases. Comparisons of quantitative variables between two groups were conducted with the Student $t$ test for independent samples. Differences between existence of subjective and objective symptoms in the same patients were estimated using McNemar test. The logistic regression model was used to evaluate the impact of age and elicitor on severity of the reaction. The results were presented as odds ratios along with respective $95 \%$ confidence intervals and respective $p$-values. A $p$-value of $<0.05$ was considered significant. IBM SPSS Statistics 25 for Windows was used for statistical analysis.

\section{Results}

Almost all (99.1\%) anaphylaxis incidents occurred in Poland, mostly at home $(n=43,37.7 \%)$ or outdoors ( $n=36,31.6 \%)$.

The most frequent triggers of anaphylaxis were insect venom ( $n=54,47.4 \%)$, food $(n=40,35.1 \%)$, drugs ( $n=6,5.3 \%)$, allergen immunotherapy (AIT) $(n=3,2.6 \%)$, and other $(n=4,3.5 \%)$. Idiopathic anaphylaxis (IA) was diagnosed in 7 (6.1\%) children (Table 1). The elicitor classification was based on the NORA database. The type of allergens varied in different age groups $(p=0.016)$.

In the group of children younger than 3 years $(n=17)$ and pre-schoolers aged $4-6$ years $(n=32)$, food was the predominant anaphylaxis trigger, in $70.6 \%(n=12)$ and $43.8 \%(n=14)$, respectively. In the age groups of preteens, 7-12 year olds $(n=40)$ and teenagers $(n=25)$, the majority of anaphylactic reactions was caused by insect venom, in 65\% $(n=26)$ and 52\% $(n=13)$, respectively.

The types of food that triggered anaphylaxis included mostly animal products such as hen's egg, cow's milk, quail egg, fish, then tree nuts, spices, and fruits, followed by peanuts and other legumes (Table 2). The most common allergic foods in the children up to 3 years were hen's egg ( $n=6,40 \%)$, cow's milk proteins $(n=3,20 \%)$, hazelnuts and sesame ( $n=2$ each, of 13.3\%). In the 4-6 years age group, the most common food aller-

Table 1. Characteristics of the study group

\begin{tabular}{|c|c|c|c|c|c|c|c|}
\hline Variable & $\begin{array}{c}\text { Insect venom } \\
n(\%)\end{array}$ & $\begin{array}{l}\text { Food } \\
n(\%)\end{array}$ & $\begin{array}{l}\text { Drugs } \\
n(\%)\end{array}$ & $\begin{array}{c}\text { AIT } \\
n(\%)\end{array}$ & $\begin{array}{l}\text { Other } \\
n(\%)\end{array}$ & $\begin{array}{c}\text { Unknown } \\
n(\%)\end{array}$ & $\begin{array}{l}\text { Total } \\
n(\%)\end{array}$ \\
\hline \multirow[t]{2}{*}{ Skin } & $54(100)$ & 39 (97.5) & \multirow[t]{2}{*}{$6(100)$} & \multirow[t]{2}{*}{$3(100)$} & \multirow[t]{2}{*}{$4(100)$} & \multirow[t]{2}{*}{7 (100) } & \multirow[t]{2}{*}{113 (99.1) } \\
\hline & & & & & & & \\
\hline \multirow[t]{2}{*}{ GI } & $26(48.1)$ & $31(77.5)$ & \multirow[t]{2}{*}{$5(83.0)$} & \multirow[t]{2}{*}{$0(0)$} & \multirow[t]{2}{*}{$4(100)$} & \multirow[t]{2}{*}{$4(57.1)$} & \multirow[t]{2}{*}{70 (61.4) } \\
\hline & $p=$ & & & & & & \\
\hline \multirow[t]{2}{*}{ RS } & 48 (88.9) & $40(100)$ & \multirow[t]{2}{*}{$6(100)$} & \multirow[t]{2}{*}{$3(100)$} & \multirow[t]{2}{*}{$4(100)$} & \multirow[t]{2}{*}{$6(85.0)$} & \multirow[t]{2}{*}{107 (93.9) } \\
\hline & $p=$ & & & & & & \\
\hline \multirow[t]{2}{*}{ CVS } & $46(85.2)$ & $26(65)$ & \multirow[t]{2}{*}{$6(100)$} & \multirow[t]{2}{*}{$1(33.3)$} & \multirow[t]{2}{*}{$1(25)$} & \multirow[t]{2}{*}{$5(71.4)$} & \multirow[t]{2}{*}{$85(74.6)$} \\
\hline & $p=$ & & & & & & \\
\hline
\end{tabular}


Table 2. Elicitors of anaphylaxis ( $n=$ number of cases)

\begin{tabular}{|c|c|c|c|}
\hline $\begin{array}{l}\text { Symptoms/ } \\
\text { Trigger }\end{array}$ & Elicitor group & Product & Recurring elicitor \\
\hline \multirow[t]{19}{*}{ Food (40) } & \multirow[t]{3}{*}{ Animal products (16) } & Hen’s egg (9) & Hen's egg (1) \\
\hline & & Cow's milk (6) & Cow's milk (5) \\
\hline & & Quail egg (1) & \\
\hline & \multirow[t]{3}{*}{ Tree nuts (6) } & Hazelnut (3) & Hazelnut (1) \\
\hline & & Walnut (2) & Walnut (1) \\
\hline & & Cashew (1) & \\
\hline & \multirow[t]{2}{*}{ Spices and others (4) } & Sesame (3) & Sesame (1) \\
\hline & & Linseeds (1) & \\
\hline & \multirow[t]{3}{*}{ Fruit (4) } & Kiwi (2) & Kiwi (2) \\
\hline & & Banana (1) & \\
\hline & & Black berry (1) & \\
\hline & \multirow[t]{2}{*}{ Peanut and other legumes (4) } & Peanut (3) & Peanut (1) \\
\hline & & Soy (1) & \\
\hline & Vegetables (1) & Celery (1) & Celery (1) \\
\hline & \multirow[t]{2}{*}{ More than one trigger suspected (2) } & Carrot and fish (1) & \\
\hline & & Sesame and sunflower seeds (1) & Sunflower seeds (1) \\
\hline & \multirow[t]{3}{*}{ Other foods (3) } & Kebab with sauce (1) & Kebab with sauce (1) \\
\hline & & Pizza (1) & \\
\hline & & Other meal (1) & Other meal (1) \\
\hline \multirow{3}{*}{$\begin{array}{l}\text { Insect venom } \\
\text { (54) }\end{array}$} & Bee (33) & & 12 \\
\hline & Wasp (18) & & 3 \\
\hline & Hornet (3) & & 2 \\
\hline \multirow[t]{5}{*}{ Drugs (6) } & \multirow[t]{2}{*}{ Analgesic (3) } & Metamizole (2) & \\
\hline & & Paracetamol (1) & \\
\hline & Local anaesthetics (1) & Articaine (1) & \\
\hline & Antibiotics (1) & Cephalosporin (1) & \\
\hline & Iron Supplement (1) & Innofer Baby (1) & \\
\hline \multirow[t]{3}{*}{ AIT (3) } & \multirow[t]{3}{*}{ SCIT (3) } & Birch + grasses + rye- Allergovit (1) & \\
\hline & & HDM-Novo helisen (1) & \\
\hline & & Bee venom extract- Pharmalgen (1) & \\
\hline \multirow[t]{2}{*}{ Other (4) } & \multirow[t]{2}{*}{ Pollens (4) } & Grass pollen natural exposure (3) & \\
\hline & & $\begin{array}{l}\text { Bee plant pollen extract (dietary } \\
\text { supplement) (1) }\end{array}$ & \\
\hline
\end{tabular}

gens included cow's milk ( $n=3,27.3 \%)$, hen's egg $(n=2$, $18.2 \%)$ and single cases of hazelnuts, peanuts, cashews, linseeds, and kiwi $(n=1,9.1 \%)$.

In 2/3 of the cases, the food allergen was pre-packaged. In half of the cases, the food volume that caused the allergic reaction did not exceed $5 \mathrm{ml}$ (1 teaspoon). Allergens in those cases were peanuts, hen's egg, quail egg, tree nuts, and sesame.
The trigger in the majority of anaphylaxis cases caused by insect venom was a bee sting (Table 2). Children with venom allergy were older (mean: $9.2 \pm 3$. years) than those with food allergy (mean: $5.9 \pm 4.9$ years, $p=0.001$ ).

Clinical manifestations of anaphylaxis typically included dermal ( $n=113,99.1 \%$ ), gastro-intestinal (GI) ( $n=70,61.4 \%)$, respiratory (RS) $(n=107,93.9 \%)$, and cardiovascular (CVS) ( $n=85,74.6 \%)$ symptoms (Table 1 ). 
A

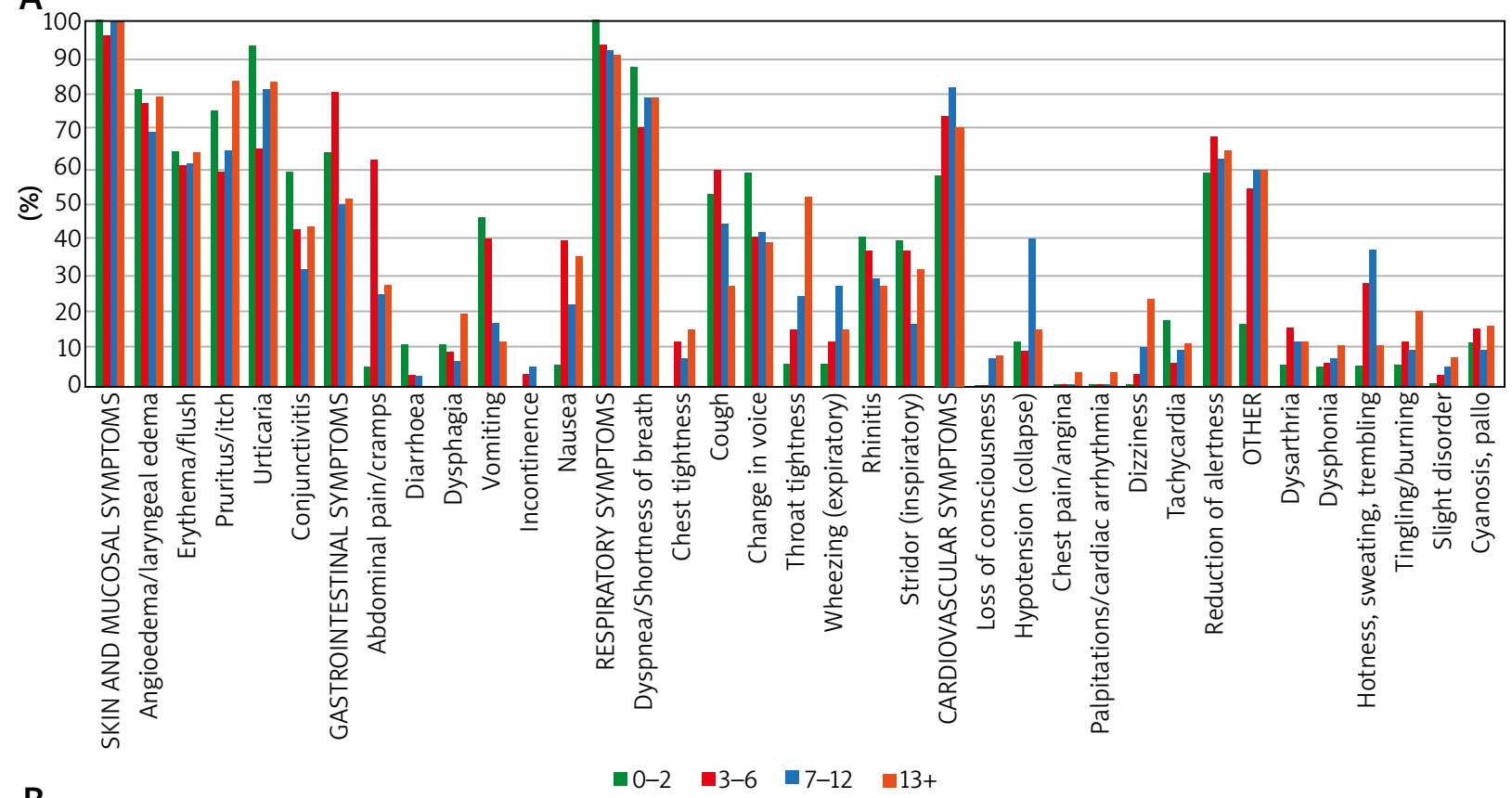

B

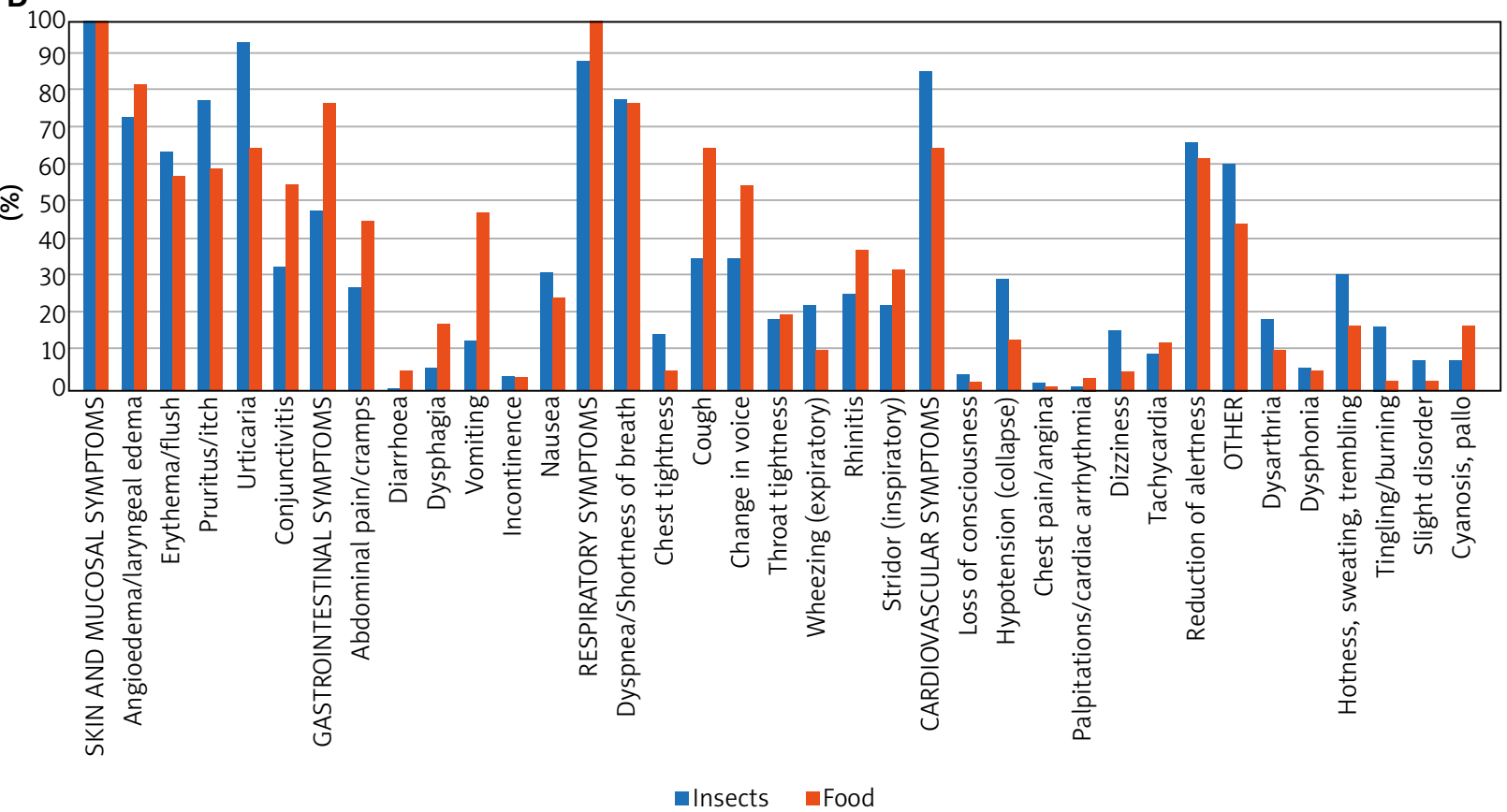

Figure 1. Frequency of the listed anaphylaxis clinical symptoms as a function of the age group (A) or a specific trigger (B). A - the age groups included ages 0-2 (green column), 3-6 (red), 7-12 (blue) and 13+ (orange). B - the trigger was either insect venom (blue) or food ingestion (orange)

The incidence of the symptoms from the gastrointestinal tract, respiratory system, or cardiovascular system varied depending whether children were allergic to insect venom or food (Table 1).

The cardiovascular symptoms developed in all the children in whom anaphylaxis was triggered by a drug, in over two thirds of patients allergic to insect venom, and in a smaller fraction of children with food allergy $(p=0.022)$. The $\mathrm{Gl}$ symptoms were diagnosed in more than $3 / 4$ of children with a drug or food allergy, and in less than half of those allergic to venom $(p=0.004)$ (Table 1$)$.

Clinical characteristics of anaphylaxis varied when evaluated in four age groups (Figure $1 \mathrm{~A}$ ). The children with Gl symptoms were younger (mean: $7.16 \pm 4.5$ years) than those without them (mean: $9.3 \pm 4.9$ years, $p=0.019$ ). The objective symptoms of anaphylaxis 

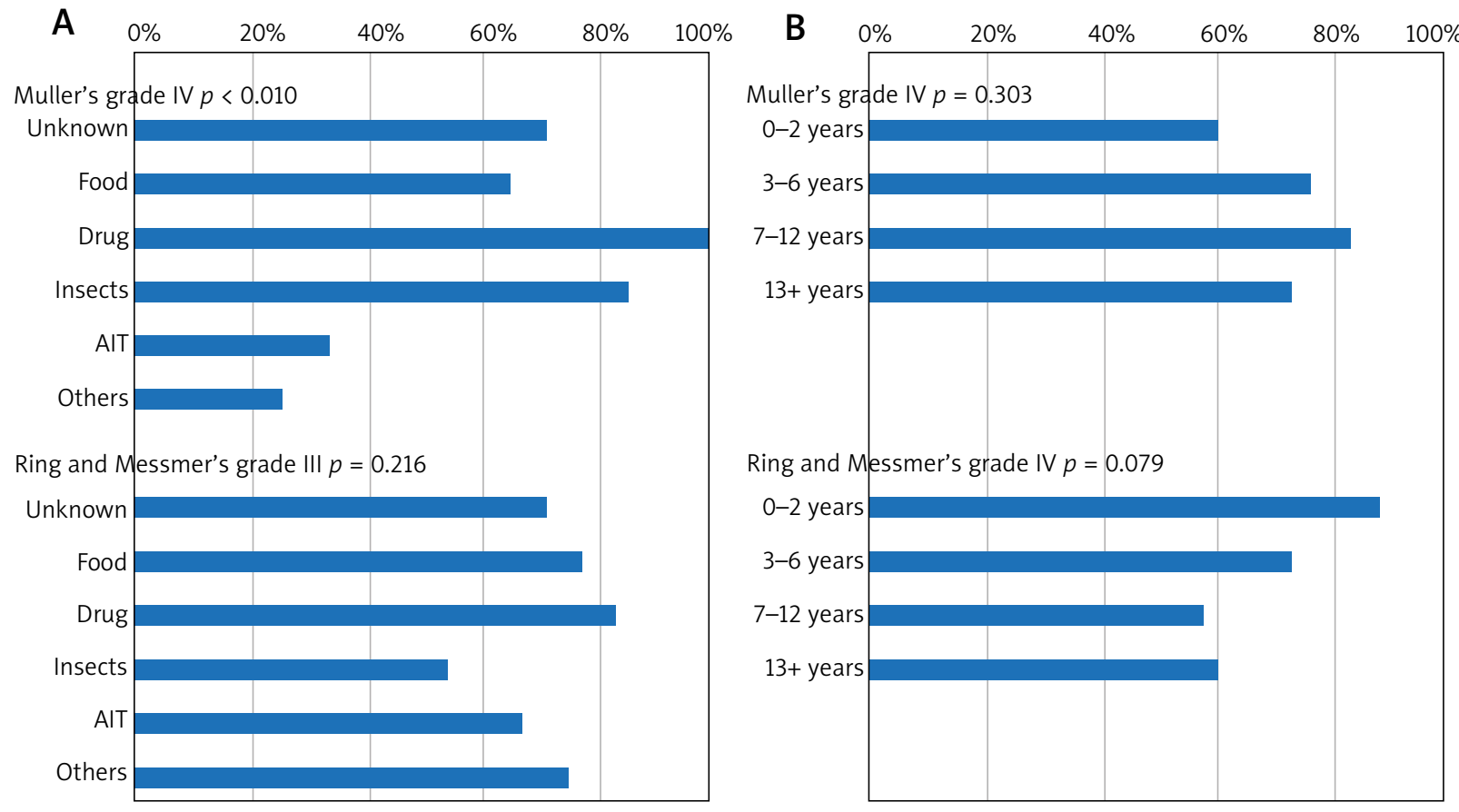

Figure 2. Frequency of grade IV and grade III anaphylaxis as a function of different anaphylaxis triggers (A) or selected age groups (B)

developed in all the patients (100\%), while the subjective symptoms were experienced by $89.5 \%$ of children ( $p<0.001)$. The objective symptoms included vomiting $(p=0.01)$, which dominated in the youngest patients aged $0-2$ years (47.1\%) followed by children aged 3-6 years $(40.6 \%)$, and hypotension $(p=0.006)$ that was predominant in the $7-12$ years age group (40\%) (Figure $1 \mathrm{~A}$ ).

The subjective symptoms included abdominal pain $(p<0.001)$ and nausea $(p=0.044)$ that dominated in the $3-6$ years age group, then throat tightness $(p=0.002)$ and dizziness ( $p=0.022)$ in the $13+$ years age group, and hotness, sweating, trembling $(p=0.027)$ in the 7-12 years age group (Figure $1 \mathrm{~A}$ ). Food-triggered anaphylaxis was significantly more often associated with conjunctivitis $(p=0.036)$, vomiting $(p<0.001)$, and cough $(p=0.04)$ (Figure $1 \mathrm{~B})$, while insect venom often resulted in tingling, burning of hands/feet $(p=0.04)$, paraesthesia, urticaria $(p<0.001)$, and hypotension $(p=0.049)$ (Figure 1 B).

Analysis of the symptoms' severity showed grade IV in 85 (74.5\%) children according to Mueller's scale, and analogous grade III in 75 (65.8\%) children according to the R\&M scale. There were significant differences in their distribution when evaluated with either Mueller's scale (grade II + III vs. IV; $p=0.028$ ) or R\&M scale (grade II vs. III; $p=0.029$ ) between selected groups of the trigger factors. The most severe anaphylaxis cases were triggered by medications according to both scales (Figure $2 \mathrm{~A}$ ).
Mueller's scale grade IV was most often diagnosed in anaphylaxis caused by medications and insect venom, while it was least common in AIT and other allergens. R\&M's grade III was the most common in the drug- and food-induced reactions, and the least common in the insect venom cases. The frequency of Mueller's grade IV increased with age, and it was the most common in the 7-12 years age group, in contrast to frequency of R\&M's grade III.

Life-threatening symptoms were observed in 26 children (mean: $9.1 \pm 3.9$ years) (14 boys), presenting as a blood pressure decrease $(n=25,22 \%)$, and/or loss of consciousness ( $n=5,4.4 \%$ ) (Table 3$)$. The youngest children were the least susceptible to develop lifethreatening reactions, which were observed in only 2 out of 17 children up to the age of 3 years (1.8\%). The most common causative agents that triggered a severe lifethreatening reaction were venoms ( $n=17,65.4 \%)$, food $(n=5,19.2 \%)$, and drugs $(n=3,11.5 \%)$. In 1 (3.8\%) case, there was no causative agent found.

In the group of 6 children allergic to medications, half of them developed a very serious case of anaphylaxis. Comparison of the frequencies of the life-threatening symptoms triggered by either food or insect sting showed that the symptoms manifested in every third child $(31.5 \%)$ allergic to insect venom and every $8^{\text {th }}$ patient $(12.5 \%)$ allergic to food $(p=0.032)$.

In 110 out of 114 evaluated children (96\%), we determined the length of time from the contact with the 
Table 3. Clinical presentation of children with potentially life-threatening anaphylaxis

\begin{tabular}{|c|c|c|c|c|c|}
\hline No. & Age [years] & Sex & Elicitor group & The most severe symptom & $\begin{array}{c}\text { How many times has this allergen } \\
\text { caused a reaction previously }\end{array}$ \\
\hline 1 & 1 & M & Hen's egg & Hypotension & 0 \\
\hline 2 & 1 & M & Sesame & $\begin{array}{l}\text { Hypotension } \\
\text { Stridor }\end{array}$ & 0 \\
\hline 3 & 4 & $\mathrm{~F}$ & Wasp & $\begin{array}{l}\text { Hypotension } \\
\text { Stridor }\end{array}$ & 0 \\
\hline 4 & 5 & $\mathrm{~F}$ & Unknown & $\begin{array}{l}\text { Hypotension } \\
\text { Stridor }\end{array}$ & 0 \\
\hline 5 & 6 & M & Wasp & Hypotension & 0 \\
\hline 6 & 7 & M & Bee & $\begin{array}{c}\text { Hypotension } \\
\text { Stridor } \\
\text { Loss of consciousness }\end{array}$ & 0 \\
\hline 7 & 7 & M & Wasp & Hypotension & 0 \\
\hline 8 & 7 & $\mathrm{~F}$ & Carrot and fish & $\begin{array}{l}\text { Hypotension } \\
\text { Stridor }\end{array}$ & 0 \\
\hline 9 & 7 & $\mathrm{~F}$ & $\begin{array}{c}\text { Fruit } \\
\text { huckleberry }\end{array}$ & Hypotension & 0 \\
\hline 10 & 8 & M & Cephalosporin & $\begin{array}{c}\text { Hypotension } \\
\text { Stridor } \\
\text { Loss of consciousness }\end{array}$ & 0 \\
\hline 11 & 8 & $\mathrm{~F}$ & Bee & Hypotension & 4 \\
\hline 12 & 9 & $\mathrm{~F}$ & Wasp & Hypotension & 0 \\
\hline 13 & 10 & $M$ & Bee & $\begin{array}{l}\text { Hypotension } \\
\text { Stridor }\end{array}$ & 0 \\
\hline 14 & 10 & $M$ & Bee & Hypotension & 0 \\
\hline 15 & 10 & M & Paracetamol & Hypotension & 0 \\
\hline 16 & 10 & $\mathrm{~F}$ & Bee & Hypotension & 0 \\
\hline 17 & 10 & $\mathrm{~F}$ & Wasp & Hypotension & 0 \\
\hline 18 & 10 & $\mathrm{~F}$ & Bee & Hypotension & 4 \\
\hline 19 & 11 & $M$ & Wasp & Hypotension & 0 \\
\hline 20 & 11 & $\mathrm{~F}$ & Pizza & $\begin{array}{c}\text { Hypotension } \\
\text { Loss of consciousness }\end{array}$ & 0 \\
\hline 21 & 11 & $\mathrm{~F}$ & Wasp & Hypotension & 1 \\
\hline 22 & 13 & M & Bee & Loss of consciousness & 1 \\
\hline 23 & 13 & $\mathrm{~F}$ & Articaine & $\begin{array}{c}\text { Hypotension } \\
\text { Stridor } \\
\text { Loss of consciousness }\end{array}$ & 0 \\
\hline 24 & 15 & $M$ & Hornet & Hypotension & 1 \\
\hline 25 & 16 & $M$ & Wasp & Hypotension & 0 \\
\hline 26 & 16 & M & Hornet & Hypotension & 0 \\
\hline
\end{tabular}

causal trigger to the first symptoms of anaphylactic shock. The above time period was less than or equal to 10 min in half of the above patients ( $n=56 / 110,50.9 \%$ ). The shortest time (0-10 min) was observed in children exposed to AIT or unknown agent $(66.7 \%$ in each of those groups), insect venom (57.4\%), food (45\%). The symptoms developed 30 min after the anaphylactic trigger's exposure in $15.5 \%$ of children.
In the group of 6 patients that developed anaphylaxis after drug administration, the majority of them ( $n=4,66.7 \%$ ) showed first symptoms after over $30 \mathrm{~min}$. There was no age difference between the children who developed anaphylaxis quickly to the ones reacting after more than $30 \mathrm{~min}(p=0.5)$. The time of development of the symptoms since the trigger exposure was not associated with the child's gender $(p=0.85)$. The time of 
occurrence of the serious, potentially life-threatening symptoms such as loss of consciousness, hypotension, stridor, wheezing, throat swelling, was not different from the one of the milder symptoms ( $p=0.774)$.

A biphasic reaction developed in 7\% $(n=8)$ of patients in the $0-10$ years age group due to allergy to food (fruit (1), hen's egg (2), cow's milk (2), bee venom (2), drug (paracetamol) and one unknown trigger, graded as grade III (all food allergens) and grade II according to R\&M scale.

\section{Multifactorial analysis}

Grade IV according to Mueller's scale was significantly less common $(p=0.028)$ in children who developed anaphylaxis triggered by the factors other than food and insects compared to the venom. There was no such a correlation found in case of R\&M grade III. Age did not affect severity of the symptoms according to either scale.

\section{Discussion}

The issue of anaphylaxis in paediatrics remains important and it is characterized by the most dynamic increase compared to the other life-threatening conditions in children, though it varies according to the geographic region [13-15]. In the US between 2008 and 2014, there was a $147 \%$ increase of the reported anaphylaxis cases in children, from 101 to 249 million children per year [16]. The main reference system for our study was the European Registry of Anaphylaxis that included data of 1970 cases of children and adolescents [17]. The data from our centre constituted $12.5 \%$ of the international part of the Registry, compromising 909 cases of children and youth (https://www.anaphylaxie.net/en/\#tabs quote-1552943379-1744-1).

\section{Age and place}

The age distribution including $43 \%$ of $0-6$ year olds, $35 \%$ of $7-12$ year olds, and $22 \%$ of $13+$ year olds, with a predominance of males (66.7\%) in our study was comparable with the European Registry data (44\%, 33\%, and $23 \%$, respectively) with the majority of boys (70\%) [17]. The high proportion of males in anaphylaxis in children was recently presented in the meta-analysis based on 59 international paediatric publications [18]. A lower fraction of boys (58\%) but a similar average age (7.4 \pm 4.7 years) compared to our work was presented by the French authors who analysed data of 160 children with anaphylaxis hospitalized in one of 18 paediatric emergency care units in the Nord-Pas-de-Calais region of France between 2015 and 2017 [19]. The majority of the presented anaphylaxis events occurred either at home ( $n=43,37.7 \%)$ or outdoors ( $n=36,31.6 \%)$, which was comparable with the European Registry data, $46 \%$ and $19 \%$ respectively [17].

\section{Triggers}

In the presented material, the most common anaphylaxis triggers were insect venom and food products. The most common food elicitors were hen's egg, cow's milk, sesame, peanuts and hazelnuts. Those allergens were predominant in the younger kids up to 3 years (70.6\%) and pre-schoolers (43.8\%). Both age distribution and type of allergens (triggers) were comparable with the Anaphylaxis Registry showing that food such as cow's milk and hen's egg caused $88 \%$ of reactions in children younger than 6 years, as well as other studies in the youngest children with anaphylaxis history [17-19]. An increasing number of paediatric reports indicated a growing role and strong allergic potential of the nuts, in particular tree nuts in the preschool children who developed allergic reactions to cashews and walnuts independent from their peanut or legumes allergy [20-22]. In our material, the tree nuts such as hazelnuts, walnuts, and cashews $(n=6)$ caused an anaphylactic reaction in children aged 0-10 years twice more often than peanuts. In the European Registry, anaphylaxis triggered by tree nuts was the most prevalent in the preschool children, $76 \%$ of children were allergic to cashews and $66 \%$ to hazelnuts in the group of 87 reported cases. At the same time, anaphylaxis due to peanuts was present in all the age groups, 325 cases out of the entire 1970 study's cohort (16\%) [17]. In this material, like in all the other centres, the majority of the anaphylactic reactions developed shortly after nut consumption, even in a small amount. In the majority of the paediatric studies, including anaphylaxis registry, the second most common trigger after food allergy is insect venom [17]. Stings by the wasp were predominant ( $n=191$ wasp stings vs. 161 bee stings) in the European Registry. Our study recorded the predominance of the children allergic to bee stings, since the majority of our patients were children of bee keepers. In contrast to the above observations, there was a recent French one-centre study from 2015-2017, in which insect venom was confirmed only in 1 case in a population of 152 children with anaphylaxis [19].

Also, in the French study, in contrast to our study (6.1\%), more children (17\%) developed IA where a trigger factor could not be identified [19]. French data were consistent with American studies, which in 2017 determined IA occurrence to be $17 \%$, almost doubling from $10 \%$ recorded at the end of the $20^{\text {th }}$ century [23]. IA was always a mark of system imperfection and limitation of diagnostic possibilities. Frequency of IA was not recorded in the European Registry.

Opposite to adults, in children confirmed drug-induced anaphylaxis occurs rarely. It is indicated both in our study as well as in the studies directly addressing the issue of drug allergy in children [24].

\section{Symptoms evaluation}

In our study, all anaphylaxis triggers caused dermatologic symptoms such as urticaria (79.8\%), angioedema (76.3\%), pruritus (69.3\%), and erythema (61.4\%). 
In the European Registry, the skin changes were recorded in $92 \%$ in the following order: urticaria (62\%), pruritus (37\%), and erythema (29\%) [17].

The French authors reported similar observations, where the skin-associated symptoms developed in $99 \%$ of children with predominant rush, then pruritus, $1 / 3$ had angioedema, $26 \%$ of children had OAS (this particular type of data was missing in the NORA questionnaire). It was surprising that there was no record of urticaria [19].

In our study, symptoms of the respiratory tract distress such as dyspnoea (78.9\%), cough (46.5\%), change in voice (43.9\%), rhinitis (43.9\%), stridor (29.8\%), throat tightness (25.4\%), and wheezing (17.5\%) were observed in $93.9 \%$ of children. These were present in all the children (100\%) with anaphylaxis induced by medication, AIT and other allergens. In the European Registry, 80\% of children developed respiratory system distress in the form of dyspnoea occurring with the same frequency in all the age groups, and about $1 / 3$ of children suffered from wheezing [17]. In the French study, only $64 \%$ of children experienced respiratory problems, including dyspnoea that developed in $56 \%$, stridor in $19 \%$, in none of them there was any bronchial obstruction, but they were present in $18 \%$ of children in the ambulatory care and ED [19].

Our data indicated that $61.4 \%$ of children manifested GI symptoms, with a significant difference between children with food allergy (77.5\%) and the ones allergic to insect venom (48.1\%). Abdominal pain was the most common GI symptom, however only vomiting was significantly predominant in the children with food allergy (48\%) compared to the insect venom (13\%) in particular in the 0-6 years age group. Similarly, the Registry data indicated GI symptoms in $45 \%$ of cases with predominant vomiting in the preschool group (27\%) and nausea in the school children (15\%) [17]. In the French study, less children developed GI symptoms (48\%), out of whom the majority reported abdominal pain (36\%) and vomiting (30\%) [19].

In this study, the cardiovascular (CV) symptoms were present in $74.6 \%$ of children. They were significantly more common in the children allergic to insect venom (85.2\%) compared to the food products (65\%), and they occurred in all the children with drug-induced anaphylaxis. The Registry recorded CV symptoms in $41 \%$ of cases, mostly in the form of dizziness, hypotension and collapse, more prevalent in the adolescents [17]. In the French study, the CV and neurological symptoms were combined and recorded as a loss of consciousness in $13 \%$ of children, and documented hypotension at the level of ED in 3\% of patients [19]. Three percent of the French parents reported altered consciousness (reduction of alertness) of their children [19]. In our study, the parents noticed an altered mental state in $64 \%$ of children, including all the patients allergic to medications and $67 \%$ of them allergic to insect venom. In the Registry, $13 \%$ of children experienced a decreased level of consciousness [17].
There is no universal tool to assess severity of anaphylaxis across the entire spectrum of symptoms, variety of age groups, different potential triggers and exposure circumstances. There is a number of heterogeneous scales out of which some are dedicated to a specific type of antigen that triggers anaphylaxis. All those instruments typically evaluate milder, not life-threatening symptoms, such as urticaria, however they might over- or underestimate more severe clinical symptoms [3]. Therefore, there are discrepancies in the severity assessment with different scales, which was further demonstrated by the multifactorial analysis in this study. According to the Registry, the majority of the anaphylactic reactions evaluated with R\&M's scale were grade III (47\%, 2 organ systems seriously affected) and grade II ( $45 \%, \geq 2$ organ systems affected); anaphylaxis was instantaneous within 10 min from the trigger exposure in 58\% of children, and it was biphasic in 5\% of children $(n=77)$ [17].

Our data were different since $62 \%$ of children developed grade III reaction and $37.7 \%$ of them had grade II according to R\&M's scale. However, the observed timeline of the events was comparable, where about half of the patients developed anaphylaxis within $10 \mathrm{~min}$, and $7 \%$ had a biphasic type of reaction.

In the Registry there were 26 (1.3\%) cases with potentially life-threatening reactions in all the age groups, including 7 cases of cardiac failure and 5 deaths caused by cow's milk, peanuts, and insect venom [17]. In our material, we did not record any deaths, however 26 (22.8\%) children developed potentially life-threatening symptoms as a result of anaphylaxis to insect venom $(n=16)$, foods $(n=5)$ and drugs $(n=3)$.

We identified 36 (31.6\%) children who developed anaphylaxis after repeated exposure to the same allergen as before. The Registry reported a comparable number of about $1 / 3$ of children experiencing anaphylaxis in the past [17]. According to the French study on the recurrence of anaphylaxis in children hospitalized at PICU in 2003-2013, the recurrence rate of anaphylaxis was $0.20 / 100$ patients/year, while food (79\%) and drugs (8\%) were the main elicitors [25].

\section{Symptomatology vs. trigger of anaphylaxis}

The differences in symptoms that varied depending on the type of the anaphylaxis trigger were also noticed by Danish researchers [3]. Their study included all the patients with the positive results of food or drug provocation tests $(n=2828)$, including 616 cases of anaphylaxis. The most frequently recorded symptoms following food challenge were urticaria (47\%), oral allergy syndrome (OAS) (35\%), abdominal pain (32\%), conjunctivitis (24\%), vomiting (24\%) and rhinorrhoea (22\%), while druginduced anaphylaxis was characterized predominantly by the skin symptoms such as pruritus (47\%), urticaria (36\%), rash (35\%) or angioedema (17\%) [3]. The patients undergoing food challenge were significantly younger than these challenged with a drug $(p<0.001)$. The Danish authors pointed out that the youngest children in the 
0-3 years group rarely had subjective symptoms, such as OAS, abdominal pain or nausea, instead more of them (63\%) had urticaria and/or rhino-conjunctivitis, compared to the older age groups (4-15 years/15+ years). The $15+$ years group presented more severe objective reactions after a challenge with peanuts (a-OR $(95 \% \mathrm{Cl}): 1.77$ (1.33-2.35)), while other food challenges in this group were significantly milder $(p=0.03)$, especially when compared to drug challenge outcomes [3]. Nevertheless, it appeared that there was a number of underdiagnosed cases of severe anaphylaxis in the youngest group of patients, in whom food was the most common causative factor. In our material, up to $80 \%$ of children aged 0-3 years demonstrated R\&M's grade III anaphylaxis. In the French study based on anaphylaxis cases recorded by the Allergy Vigilance Network from 2002 to 2018, it is pointed out that hypotension in young children (02 years) might be underdiagnosed [22]. According to their data, hypotension occurred in $21 \%$ of infants, which was significantly more frequent in comparison to preschool children ( $p=0.004$ ) [22]. Regardless of the age, all the children should undergo objective evaluation of their symptoms, including monitoring of blood pressure, heart rate, capillary refill time, and saturation if possible in order not to overlook any of these symptoms [26, 27].

The French authors carried out a detailed comparison of the symptoms resulting from antibiotics versus NSAIDs in children [3]. Our study included mostly children allergic to insect venom or foods; therefore we analysed those two groups. We observed that the children allergic to food were younger. Both groups almost always developed symptoms affecting their skin and mucous membranes.

In case of food-induced anaphylaxis, the Gl tract (77.5\% vs. 48.1\%, $p=0.004)$ and respiratory tract $(100 \%$ vs. $88.9 \%, p=0.036$ ) associated symptoms were significantly more common compared to the insect venom. In contrast, anaphylaxis resulting from insect venom mostly affected the CV system ( $85.2 \%$ vs. $65 \%, p=0.022$ ).

It is suggested that similarly to asthma, we may expect some differences between anaphylaxis caused by food vs. non-food triggers, with respect to different anaphylaxis endotypes, based on different pathophysiological patterns, which may vary in clinical manifestations [28].

This is a retrospective study. Additionally, our department serves as the reference centre for diagnostics and treatment of insect venom-induced anaphylaxis in Southern Poland. We could not verify our data with respect to bias since there were no other extensive epidemiological studies of anaphylaxis triggers in children in Poland [29].

\section{Conclusions}

Clinical manifestations of anaphylaxis in children are both trigger and age dependent. Dermal and respiratory symptoms are present in almost all children. The phe- notype of the patient with food anaphylaxis presents as a younger child with mostly GI symptoms, while the phenotype of the patient with venom anaphylaxis presents as an older child with mostly cardiovascular symptoms. Evaluation of the objective symptoms should be obligatory in all age groups.

\section{Acknowledgments}

We are grateful to our patients and to their caregivers for their agreement to participate in this study.

\section{Conflict of interest}

The authors declare no conflict of interest.

\section{References}

1. NIAID-Sponsored Expert Panel, Boyce JA, Assa'ad A, et al. Guidelines for the diagnosis and management of food allergy in the United States: report of the NIAID-sponsored expert panel. J Allergy Clin Immunol 2010; 126 (6 Suppl): 1-58.

2. Goetz VL, Kim K, Stang AS. Pediatric anaphylaxis in the emergency department: clinical presentation, quality of care, and reliability of consensus criteria. Pediatr Emerg Care 2019; 35: 28-31.

3. Eller E, Muraro A, Dahl R, et al. Assessing severity of anaphylaxis: a data-driven comparison of 23 instruments. Clin Transl Allergy 2018; 8: 29.

4. Biló BM, Rueff F, Mosbech H, et al.; EAACl Interest Group on Insect Venom Hypersensitivity. Diagnosis of Hymenoptera venom allergy. Allergy 2005; 60: 1339-49.

5. Sampson HA. Anaphylaxis and emergency treatment. Pediatrics 2003; 111: 1601-8.

6. Cox LS, Sanchez-Borges M, Lockey RF. World Allergy Organization systemic allergic reaction grading system: is a modification needed? J Allergy Clin Immunol Pract 2017; 5: 58-62. e5.

7. Brown SG. Anaphylaxis: clinical concepts and research priorities. Emerg Med Australas 2006; 18: 155-69.

8. Muraro A, Fernandez-Rivas M, Beyer K, et al. The urgent need for a harmonized severity scoring system for acute allergic reactions. Allergy 2018; 73: 1792-800.

9. Sundquist BK, Jose J, Pauze D, et al. Anaphylaxis risk factors for hospitalization and intensive care: a comparison between adults and children in an upstate New York emergency department. Allergy Asthma Proc 2019; 40: 41-7.

10. Ponce Guevara LV, Laffond Yges E, Gracia Bara MT, et al. Adherence to anaphylaxis guidelines: real-world data from the Emergency Department of a Tertiary Hospital. J Investig Allergol Clin Immunol 2018; 28: 246-52.

11. Bilò MB, Pravettoni V, Bignardi D, et al. Hymenoptera venom allergy: management of children and adults in clinical practice. J Investig Allergol Clin Immunol 2019; 29: 180-205.

12. Tarczoń I, Jedynak-Wąsowicz U, Lis G, et al. Intervention in anaphylaxis: the experience of one paediatric centre based on NORA reports. Adv Dermatol Allergol 2020. doi: 10.5114/ ada.2019.89715.

13. Tham EH, Leung ASY, Pacharn P, et al. Anaphylaxis - lessons learnt when East meets West. Pediatr Allergy Immunol 2019; 30: 681-8. 
14. Turner PJ, Campbell DE, Motosue MS, et al. Global trends in anaphylaxis epidemiology and clinical implications. J Allergy Clin Immunol Pract 2020; 8: 1169-76.

15. Österlund J, Winberg A, West CE. A 10-year review found increasing incidence trends of emergency egg allergy reactions and food-induced anaphylaxis in children. Acta Paediatr 2019; 108: 314-20.

16. Michelson KA, Hudgins JD, Burke LG, et al. Trends in severe pediatric emergency conditions in a National Cohort, 2008 to 2014. Pediatr Emerg Care 2018; 10. Doi: 1097/ PEC.0000000000001409.

17. Grabenhenrich LB, Dölle S, Moneret-Vautrin A, et al. Anaphylaxis in children and adolescents: the European Anaphylaxis Registry. J Allergy Clin Immunol 2016; 137: 1128-37.e1.

18. Wang Y, Allen KJ, Suaini NHA, et al. The global incidence and prevalence of anaphylaxis in children in the general population: a systematic review. Allergy 2019; 74: 1063-80.

19. Pouessel G, Antoine M, Lejeune S, et al. The time course of anaphylaxis manifestations in children is diverse and unpredictable. Clin Exp Allergy 2020; 50: 117-20.

20. Matias J, Gaspar A, Borrego LM, et al. Tree nuts anaphylaxis in preschool age children. Eur Ann Allergy Clin Immunol 2020; doi: 10.23822/EurAnnACl.1764-1489.128.

21. Blazowski L, Majak P, Kurzawa R, et al. Food allergy endotype with high risk of severe anaphylaxis in children-monosensitization to cashew 2S albumin Ana o 3. Allergy 2019; 74: 1945-55.

22. Pouessel G, Jean-Bart C, Deschildre A, et al. Food-induced anaphylaxis in infancy compared to preschool age: a retrospective analysis. Clin Exp Allerg 2020; 50: 74-81.

23. Chan S, John RM. Idiopathic anaphylaxis: what you do not know may hurt you. J Am Assoc Nurse Pract 2020; 32: 81-8.

24. Piccorossi A, Liccioli G, Barni S, et al. Epidemiology and drug allergy results in children investigated in allergy unit of a tertiary-care paediatric hospital setting. Ital J Pediatr 2020; 46: 5.

25. Pouessel G, Cerbelle V, Lejeune S, et al. Anaphylaxis admissions in pediatric intensive care units: follow-up and risk of recurrence. Pediatr Allergy Immunol 2019; 30: 341-7.

26. Simons FE, Sampson HA. Anaphylaxis: unique aspects of clinical diagnosis and management in infants (birth to age 2 years). J Allergy Clin Immunol 2015; 135: 1125-31.

27. Greenhawt M, Gupta RS, Meadows JA, et al. Guiding principles for the recognition, diagnosis, and management of infants with anaphylaxis: an expert panel consensus. J Allergy Clin Immunol Pract 2019; 7: 1148-56.e5.

28. Chong KW, Ruiz-Garcia M, Patel N, et al. Reaction phenotypes in IgE-mediated food allergy and anaphylaxis. Ann Allergy Asthma Immunol 2020; 124: 473-8.

29. Jahnz-Rozyk K, Raciborski F, Śliwczyński AM, et al. Anaphylaxis in Poland: the epidemiology and direct costs. Adv Dermatol Allergol 2017; 34: 573-9. 